\title{
A Numerical Analysis of Fluid Flow and Heat Transfer Characteristics of ZnO-Ethylene Glycol Nanofluid in Rectangular Microchannels
}

\author{
Cuneyt Uysal* - Kamil Arslan - Huseyin Kurt \\ Karabuk University, Mechanical Engineering Department, Turkey
}

The fluid flow and heat transfer characteristics of ZnO-Ethylene glycol (EG) nanofluid through rectangular microchannels having different aspect ratios ( $\alpha$ is 1 to 2 ) are numerically investigated. The different nanoparticle volume percentages ( $\varphi$ is $1 \%$ to $4 \%$ ) of ZnO-EG nanofluid are used. The flow is considered under single-phase, three-dimensional, steady-state, incompressible, thermally developing, laminar flow conditions. As a result, the microchannel with an aspect ratio value of 1 has the highest convection heat transfer coefficient and the lowest pressure drop. It is also observed that the convection heat transfer coefficient and pressure drop increases with an increase in nanoparticle volume fraction value of nanofluid. However, the Nusselt number decreases with increasing nanoparticle volume fraction, while the Darcy friction factor is not affected.

Keywords: convection heat transfer, pressure drop, rectangular microchannel, ZnO-EG nanofluid

Highlights

- ZnO-EG nanofluid flow and convective heat transfer characteristics through rectangular microchannels are numerically investigated.

- Thermal and hydrodynamic performances of rectangular microchannels are performed for different aspect ratios.

- Results showed that the thermal and hydrodynamic performances decrease with an increase in the aspect ratio of the rectangular microchannel.

- $\quad$ The Nusselt number decreases with increase in nanoparticle volume fraction of ZnO-EG nanofluid, while the Darcy friction factor is not affected.

\section{INTRODUCTION}

Nanofluids are prepared with the addition of nanosized metallic or non-metallic particles to conventional working fluids to enhance their heat transfer ability. The term "nanofluid" was introduced by Choi [1] in 1995. In recent decades, the use of nanofluids as a heat transfer fluid in microchannel applications which are used in electronic device cooling has been investigated.

Azizi et al. [2] investigated the thermal performance of $\mathrm{Cu}$-water nanofluid through a rectangular microchannel assembled into a cylindrical geometry. The Nusselt number is enhanced up to $23 \%$ for $0.3 \mathrm{wt} \%$ nanoparticle addition. Rimbault et al. [3] reported that the $\mathrm{CuO}$-water nanofluid flow through rectangular microchannels has the higher pressure drop by $70 \%$ with a $4.5 \%$ nanoparticle addition. However, the ratio of the amount of heat transferred to the pumping power required decreases with an increase in nanoparticle volume fraction. Kalteh [4] has compared different nanofluids which are a combination of nine different nanoparticle and three different base fluids. The highest and the lowest heat transfer coefficients were obtained for diamond-water and $\mathrm{SiO}_{2}$-water nanofluid, respectively. However, the obtained pressure drop values for all nanofluid type in same base fluid were almost equal. Halelfadl et al. [5] have investigated fluid flow and heat transfer characteristics of CNT-water nanofluid through the rectangular microchannel. It was found that the nanofluid use reduces the total thermal resistance. Zhang et al. [6] have studied the fluid flow and heat transfer characteristics of $\mathrm{Al}_{2} \mathrm{O}_{3}$-water nanofluid through circular microchannels. The Nusselt number increased with increase in nanoparticle volume fraction and the Reynolds number. The maximum heat transfer enhancement was reported to be $10.6 \%$, while the Darcy friction factor increased by $7.9 \%$. Nebbati and Kadja [7] found that $\gamma \mathrm{Al}_{2} \mathrm{O}_{3}$-water nanofluid use in microchannels increased the local Nusselt number and decreased the bottom surface temperature and shear stress on the wall.

Mohammed et al. [8] numerically studied the fluid flow and heat transfer characteristics of $\mathrm{Al}_{2} \mathrm{O}_{3}$ water nanofluid having different nanoparticle volume fractions through a rectangular microchannel. It was found that the heat transfer coefficient and wall shear stresses increase with increasing nanoparticle volume fraction, while thermal resistance decreases. Mohammed et al. [9] numerically compared the nanofluids prepared with the addition of $\mathrm{Al}_{2} \mathrm{O}_{3}, \mathrm{Ag}$, 
$\mathrm{CuO}$, diamond, $\mathrm{SiO}_{2}$ and $\mathrm{TiO}_{2}$ to water. The highest and the lowest heat transfer coefficients were obtained for the diamond-water and the $\mathrm{Al}_{2} \mathrm{O}_{3}$-water nanofluids, respectively. Moreover, the highest and the lowest pressure drops were obtained for $\mathrm{SiO}_{2}$-water and Ag-water nanofluids, respectively. Salman et al. [10] compared the thermal performances of $\mathrm{Al}_{2} \mathrm{O}_{3}$-water and $\mathrm{SiO}_{2}$-water nanofluid flows through microtubes, numerically and experimentally. They found that $\mathrm{SiO}_{2}$-water nanofluid has the highest Nusselt number value and followed by $\mathrm{Al}_{2} \mathrm{O}_{3}$-water nanofluid and pure water, respectively. Mohammed et al. [11] numerically compared the thermal performances of $\mathrm{Al}_{2} \mathrm{O}_{3}$-water, Ag-water, $\mathrm{SiO}_{2}$-water and $\mathrm{TiO}_{2}$-water nanofluids through a square microchannel heat exchanger. The highest heat transfer coefficient was obtained for $\mathrm{Al}_{2} \mathrm{O}_{3}$-water nanofluid. Moreover, the lowest pressure drop was obtained for Ag-water nanofluid.

The thermophysical properties of working fluid are critical parameters of the thermal performance of working fluid, because the thermal performance parameters such as heat transfer rate, thermal diffusion, the Prandtl number, and the Reynolds number are related to thermophysical properties of working fluid. Therefore, the definition of thermophysical properties of nanofluids is a critical topic in the investigation of the thermal performance of nanofluids. Vajjha and Das [12] proposed a correlation to calculate the specific heat of nanofluids. In their study, $\mathrm{Al}_{2} \mathrm{O}_{3}$-EG/ water (60:40), $\mathrm{ZnO}-\mathrm{EG} /$ water $(60: 40), \mathrm{SiO}_{2}$-EG/water (60:40) nanofluids were used. They reported that the nanoparticle addition to base fluid decreased the specific heat of base fluid. Satti et al. [13] measured the specific heat of five different nanofluids containing $\mathrm{Al}_{2} \mathrm{O}_{3}, \mathrm{ZnO}, \mathrm{CuO}, \mathrm{TiO}_{2}$, and $\mathrm{SiO}_{2}$ nanoparticles dispersed in a base fluid of $60 \%$ propylene glycol and $40 \%$ water by mass. It was found that the specific heat decreases with increase in nanoparticle volume fraction. At $243 \mathrm{~K}$, specific heats of $\mathrm{ZnO}-\mathrm{PG} /$ water (60:40) nanofluids for $0.5 \%$ and $4.0 \%$ nanoparticle addition reduce by about $28 \%$ and $32 \%$, respectively. Esfe and Saedodin [14] and [15] proposed correlations to determine the thermal conductivity and viscosity of $\mathrm{ZnO}-\mathrm{EG}$ nanofluids. Yu et al. [16] found that in low volume concentrations of $\mathrm{ZnO}-\mathrm{EG}$ nanofluid showed Newtonian behavior, while at higher volume concentrations it showed shear-thinning behavior. Prajapati et al. [17] reported that the heat transfer coefficient increases with an increase in nanoparticle volume fraction of the $\mathrm{ZnO}$-water nanofluid. Salman et al. [18] found that the highest Nusselt number was obtained for $\mathrm{SiO}_{2}$-EG nanofluid, followed by $\mathrm{ZnO}$ $\mathrm{EG}, \mathrm{CuO}-\mathrm{EG}, \mathrm{Al}_{2} \mathrm{O}_{3}$-EG and pure $\mathrm{EG}$.
EG and EG/water mixtures are used in car engines, heating systems, and solar heating installations as heat transfer fluids in cold regions. Nanofluid-based EG and EG/water mixtures can be used as alternative heat transfer fluids in these fields. Therefore, the fluid flow and heat transfer characteristics of nanofluid-based EG should clearly be investigated. From the above literature survey, it was clearly seen that the studies performed on the fluid flow and heat transfer characteristics of $\mathrm{ZnO}-\mathrm{EG}$ nanofluid in microchannels are limited. In this study, the fluid flow and heat transfer characteristics of ZnO-EG nanofluid for different nanoparticle volume fractions through rectangular microchannels having different aspect ratios were numerically investigated under laminar flow conditions to investigate the use of $\mathrm{ZnO}-\mathrm{EG}$ nanofluid as a heat transfer fluid in electronic device cooling and the importance of geometric configuration. The dimensionless temperatures, convective heat transfer coefficient, the Nusselt number, pressure drop, the Darcy friction factor values for $\mathrm{ZnO}-\mathrm{EG}$ nanofluid were determined.

\section{NUMERICAL PROCEDURE}

\subsection{Model Description}

The system is considered to be a microchannel attached over a hot surface to dissipate heat generated by any electronic device (e.g. computer chips). The bottom wall of the microchannel is exposed to heat generated by the electronic device. The schematic diagram of the rectangular microchannel is illustrated in Fig. 1. Six different aspect ratios between $\alpha$ is 1 and 2 are defined. The hydraulic diameter and length of the microchannel for each aspect ratio values of the microchannel are assumed $150 \mu \mathrm{m}$ and $5 \mathrm{~cm}$, respectively. The other geometric parameters are defined by using the following equation,

$$
D_{h}=\frac{4 A}{P}=\frac{2 H W}{(H+W)},
$$

where $D_{h}, H$ and $W$ are the hydraulic diameter, height and weight of microchannel, respectively.

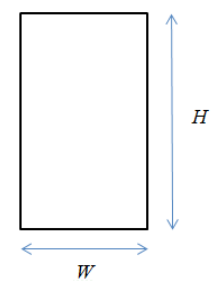

Fig. 1. The schematic diagram of microchannel 
The obtained results for other geometric parameters belonging to the rectangular microchannel are shown in Table 1.

Table 1. The geometric dimensions of microchannels

\begin{tabular}{ccc}
\hline$\alpha(H / W)$ & $H[\mu \mathrm{m}]$ & $W[\mu \mathrm{m}]$ \\
\hline 1.0 & 150 & 150 \\
\hline 1.2 & 165 & 137.5 \\
\hline 1.4 & 180 & 128.57 \\
\hline 1.6 & 195 & 121.875 \\
\hline 1.8 & 210 & 116.67 \\
\hline 2.0 & 225 & 112.5 \\
\hline
\end{tabular}

\subsection{Governing Equations}

Fluid flow containing infinitesimal solid particles with diameters less than $100 \mathrm{~nm}$ can be modeled as single-phase flow [19]. Therefore, the ZnO-EG nanofluid flow is modelled as single-phase flow in this study. The following assumptions are also adopted for this study: (i) both heat transfer and fluid flow in microchannel are in three dimensional and steady-state; (ii) nanofluid flow is incompressible and laminar; (iii) the physical properties of nanofluid, such as density, specific heat, thermal conductivity are temperature independent; and (iv) the buoyancy effect, viscous dissipation and radiation heat transfer are negligible. The governing equations for the singlephase model can be written as follows under the abovementioned assumptions:

Continuity equation:

$$
\frac{\partial U}{\partial X}+\frac{\partial V}{\partial Y}+\frac{\partial W}{\partial Z}=0
$$

$\mathrm{X}$-momentum equation:

$$
\begin{gathered}
\left(U \frac{\partial U}{\partial X}+V \frac{\partial U}{\partial Y}+W \frac{\partial U}{\partial Z}\right)= \\
=-\frac{d P}{d X}+\frac{1}{R e}\left(\frac{\partial^{2} U}{\partial X^{2}}+\frac{\partial^{2} U}{\partial Y^{2}}+\frac{\partial^{2} U}{\partial Z^{2}}\right),
\end{gathered}
$$

Y-momentum equation:

$$
\begin{gathered}
\left(U \frac{\partial V}{\partial X}+V \frac{\partial V}{\partial Y}+W \frac{\partial V}{\partial Z}\right)= \\
=-\frac{d P}{d Y}+\frac{1}{R e}\left(\frac{\partial^{2} V}{\partial X^{2}}+\frac{\partial^{2} V}{\partial Y^{2}}+\frac{\partial^{2} V}{\partial Z^{2}}\right),
\end{gathered}
$$

Z-momentum equation:

$$
\begin{gathered}
\left(U \frac{\partial W}{\partial X}+V \frac{\partial W}{\partial Y}+W \frac{\partial W}{\partial Z}\right)= \\
=-\frac{d P}{d Z}+\frac{1}{R e}\left(\frac{\partial^{2} W}{\partial X^{2}}+\frac{\partial^{2} W}{\partial Y^{2}}+\frac{\partial^{2} W}{\partial Z^{2}}\right),
\end{gathered}
$$

Energy equation:

$$
\begin{gathered}
\left(U \frac{\partial \theta}{\partial X}+V \frac{\partial \theta}{\partial Y}+W \frac{\partial \theta}{\partial Z}\right)= \\
=\frac{1}{R e \cdot \operatorname{Pr}}\left(\frac{\partial^{2} \theta}{\partial X^{2}}+\frac{\partial^{2} \theta}{\partial Y^{2}}+\frac{\partial^{2} \theta}{\partial Z^{2}}\right),
\end{gathered}
$$

where $X, Y$, and $Z$ are dimensionless distances; $U, V$, and $W$ are the dimensionless velocity components; $R e$ is the Reynolds number; $P r$ is the Prandtl number; $P$ is the dimensionless pressure and $\theta$ is the dimensionless temperature.

The dimensionless parameters in the above equations can be expressed as follows:

$$
\begin{gathered}
X=\frac{x}{D_{h}}, \quad Y=\frac{y}{D_{h}}, \quad Z=\frac{z}{D_{h}}, \\
U=\frac{u}{U_{i n}}, \quad V=\frac{v}{U_{i n}}, \quad W=\frac{w}{U_{i n}}, \\
R e=\frac{\rho U_{i n} D_{h}}{\mu}, \\
\operatorname{Pr}=\frac{C_{P} \mu}{k}, \\
P=\frac{\Delta P}{\rho U_{i n}^{2}}, \\
\theta=\frac{T-T_{i n}}{T_{w}-T_{i n}},
\end{gathered}
$$

where $u, v, w$ are the velocity components in $x, y$ and $z$ coordinates; $\rho$ is the density; $\mu$ is the viscosity; $C_{P}$ is the specific heat; $k$ is the thermal conductivity; $\Delta P$ is the pressure drop; $U_{i n}$ is the inlet velocity; $T_{w}$ and $T_{i n}$ are the wall and inlet temperature, respectively.

To solve the governing equations, boundary conditions are required. The inlet velocity is obtained by considering the Reynolds numbers. The no-slip condition is imposed at the walls of the microchannel. The fixed heat flux is applied at the bottom surface of the microchannel, and the heat is transferred from the bottom wall to the nanofluid. The side and top surfaces of the microchannel are assumed to be insulated. The pressure outlet boundary condition is used at the outlet of the microchannel. The boundary conditions used in this study are given below in detail: 
at the inlet: $\quad U=1, \quad \theta=1$,

at the outlet: $\quad P=P_{\text {out }}=0$,

at the solid-fluid interfaces:

$$
U=0, \quad \theta=\theta_{s}, \quad-k \frac{\partial \theta}{\partial n}=-k_{s} \frac{\partial \theta_{s}}{\partial n},
$$

at the bottom surface: $q_{w}^{\prime \prime}=-k_{s} \frac{\partial \theta_{s}}{\partial n}$,

at the side and top surfaces: $q_{w}^{\prime \prime}=0$.

\subsection{Thermophysical Properties}

The governing equations include some thermophysical properties belonging to working fluid. To solve the governing equations, these thermophysical properties should be defined.

The density and specific heat of the $\mathrm{ZnO}-\mathrm{EG}$ nanofluid can be determined using the following equations, which are based on conventional mixture theory, respectively:

$$
\begin{gathered}
\rho_{n f}=(1-\varphi) \rho_{b f}+\varphi \rho_{n p}, \\
\left(\rho C_{P}\right)_{n f}=(1-\varphi)\left(\rho C_{P}\right)_{b f}+\varphi\left(\rho C_{P}\right)_{n p},
\end{gathered}
$$

where $\varphi$ is the nanoparticle volume fraction of the nanofluid and the subscripts $n f, n p$ and $b f$ denote nanofluid, nanoparticle, and the base fluid, respectively.

To calculate the thermal conductivity of $\mathrm{ZnO}-\mathrm{EG}$ nanofluid, the following correlation proposed by Esfe and Saedodin [14], which is based on experimental data obtained for $\mathrm{ZnO}-\mathrm{EG}$ nanofluid can be used;

$$
k_{n f}=\left(0.24859 T^{2.504 \varphi^{0.7974}}+0.7492\right) k_{b f}
$$

where $T$ is the temperature and in units of ${ }^{\circ} \mathrm{C}$. The validity of this correlation is in $\varphi=0.0625 \%$ to $5 \%$ and $T=25{ }^{\circ} \mathrm{C}$ to $50{ }^{\circ} \mathrm{C}$ intervals.

The viscosity of $\mathrm{ZnO}-\mathrm{EG}$ nanofluid can be calculated by using following correlation proposed by Esfe and Saedodin [15] which is based on experimental data obtained for $\mathrm{ZnO}-\mathrm{EG}$ nanofluid;

$\mu_{n f}=\left(\begin{array}{l}0.9118 \operatorname{Exp}\left(5.49 \varphi-0.00001359 T^{2}\right)+ \\ +0.0303 \operatorname{Ln}(T)\end{array}\right) \mu_{b f}$,

where $T$ is the temperature and in units of ${ }^{\circ} \mathrm{C}$. This correlation is valid for $\varphi=0.25 \%$ to $5 \%$ and $T=25{ }^{\circ} \mathrm{C}$ to $50{ }^{\circ} \mathrm{C}$.

\subsection{Numerical Procedure}

To carry out the numerical computation, the finite volume method is used. The governing equations are solved along with boundary conditions. The convective terms existing in the governing equations are discretized by using the second order upwind scheme. The standard scheme is employed in the discretization of pressure. A SIMPLE algorithm is used to resolve the velocity and pressure coupling [20]. The SIMPLE-code family is based on the spatial integration of the conservation equations over finite control volumes. The Green-Gauss cell-based method is used to discretize the momentum and energy equations. The governing equations are iterated until the convergence value of $1 \times 10^{-6}$. No convergence problems are observed during the calculations.

\subsection{Grid Testing and Validation}

In the modelling of the rectangular microchannel, the hexahedral mesh distribution is used. Finer meshes are used in the region near the microchannel walls to enhance the accuracy of the solution. The mesh distribution of rectangular microchannel is shown in Fig. 2.

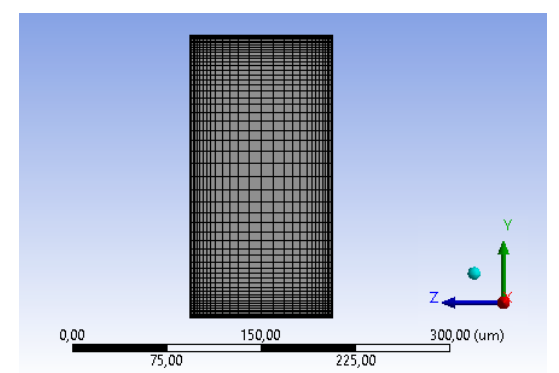

Fig. 2. The mesh distribution of rectangular microchannel

The grid independence test is realized for each microchannel with different aspect ratios to invalidate the effect of grid number on a solution. Six different grid numbers ranging from 40,000 to $1,400,000$ are used to model each microchannel. Optimum grid numbers are defined considering the change of result obtained by the solution. The numerical computations are realized for defined optimum models.

To validate the accuracy of code, the results obtained by the present study are compared with the results of Lee et al. [21], which are based on experimental data for rectangular microchannels in thermally developing laminar flow under constant heat flux conditions. The comparison of the results obtained by the present study with that of Lee et al. 
[21] is illustrated in Fig. 3. As can be seen, the local Nusselt number values obtained by the present study showed good agreement with the results of Lee et al. [21]. The maximum deviation from the results of Lee at al. [21] is obtained to be $9.45 \%$.

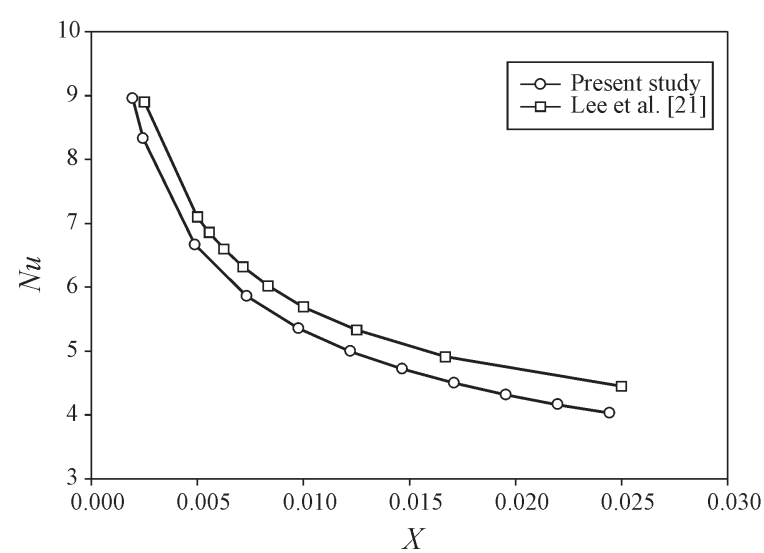

Fig. 3. Comparison of results obtained by present study with the results of Lee et al. [21]

\section{RESULTS AND DISCUSSION}

The fluid flow and heat transfer characteristics of ZnO-EG nanofluid through rectangular microchannels are numerically investigated. In the calculations, different nanoparticle volume fractions $(\varphi=1 \%$ to $4 \%$ ) of $\mathrm{ZnO}-\mathrm{EG}$ nanofluid are used. The Reynolds number is in the range of 10 to 100 . The calculations are realized for different aspect ratio values $(\alpha=1,1.2$, $1.4,1.6,1.8,2)$ of the rectangular microchannel. The fixed heat flux of $1000 \mathrm{~W} / \mathrm{m}^{2}$ is applied at the bottom surface of the microchannels.

\subsection{Dimensionless Temperature}

The dimensionless temperature is calculated by using Eq. (12). The variation of dimensionless temperature along with axial dimensionless distance for each aspect's ratio values of the rectangular microchannel in the use of pure EG at $R e=10$ and $R e=100$ are illustrated in Figs. 4a and b, respectively.

The variation of the dimensionless temperature along with the axial dimensionless distance for different nanoparticle volume fractions in $\alpha=1$ at $R e=10$ and $R e=100$ are illustrated in Figs. 5a and b, respectively.

The $\mathrm{ZnO}$ nanoparticle addition to pure EG decreased the bulk and wall temperature of the fluid. However, the decrease in wall temperature is higher than that of the bulk temperature. Therefore, the
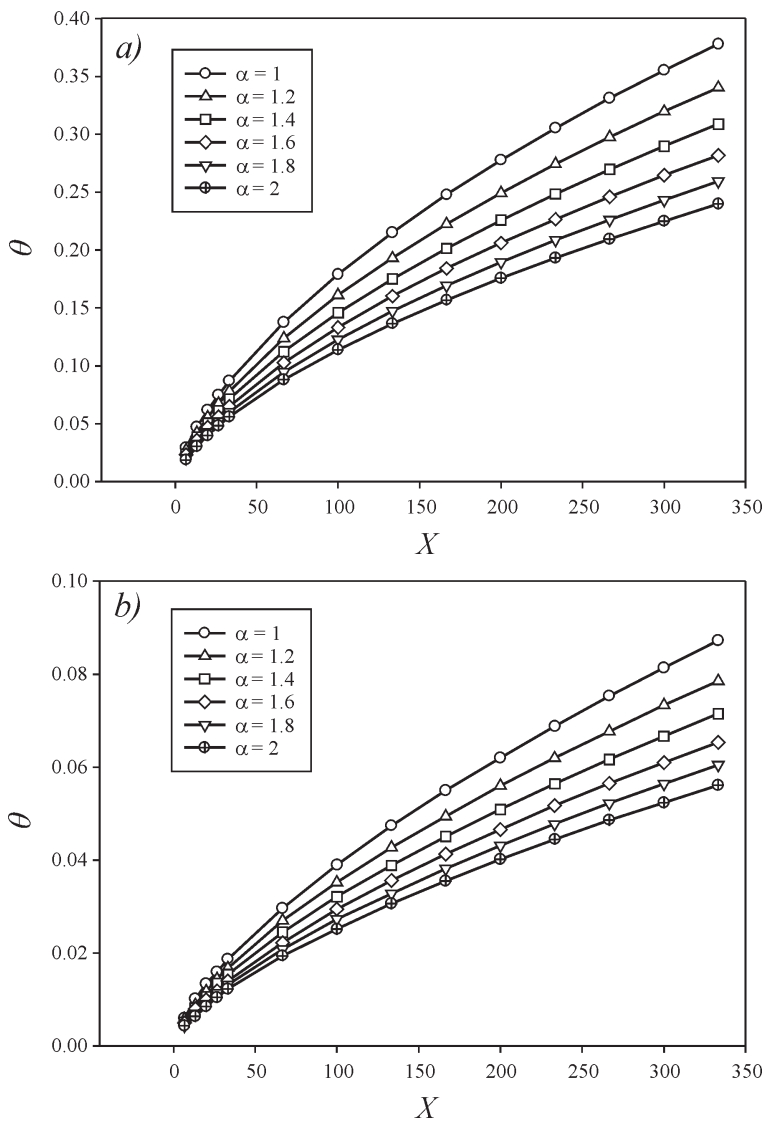

Fig. 4. The variation of dimensionless temperature along with axial dimensionless distance for different aspect ratios (working fluid is pure $E G$ ) at a) $R e=10$ and b) $R e=100$

dimensionless temperature increases with an increase in the nanoparticle volume fraction of $\mathrm{ZnO}$ nanofluid.

\subsection{Convective Heat Transfer Coefficient}

The convective heat transfer coefficient can be written as follows:

$$
h=\frac{\dot{m} C_{P}\left(T_{\text {outlet }}-T_{\text {inlet }}\right)}{A_{s}\left(T_{w}-T_{b}\right)},
$$

where $\dot{m}$ is the mass flow rate, and $A_{s}$ is the heated surface area of the microchannel.

The variation of convective heat transfer coefficient with the Reynolds number for each aspect ratio of the rectangular microchannel in the use of pure EG is illustrated in Fig. 6.

As can be seen from Fig. 6, the convective heat transfer coefficient decreases with an increase in aspect ratio of the rectangular microchannel. The convective heat transfer coefficients obtained for $\alpha=1$ 

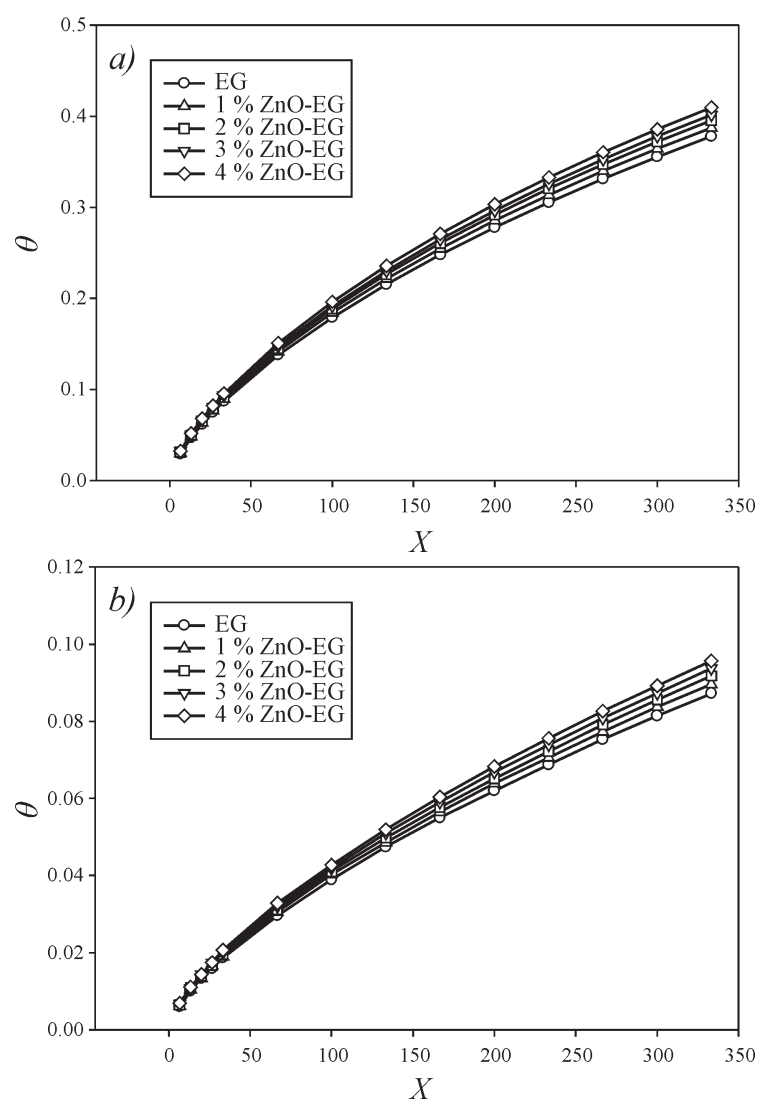

Fig. 5. The variation of dimensionless temperature along with axial dimensionless distance for different nanoparticle volume fractions (for $\alpha=1$ ) at a) $R e=10$ and b) $R e=100$

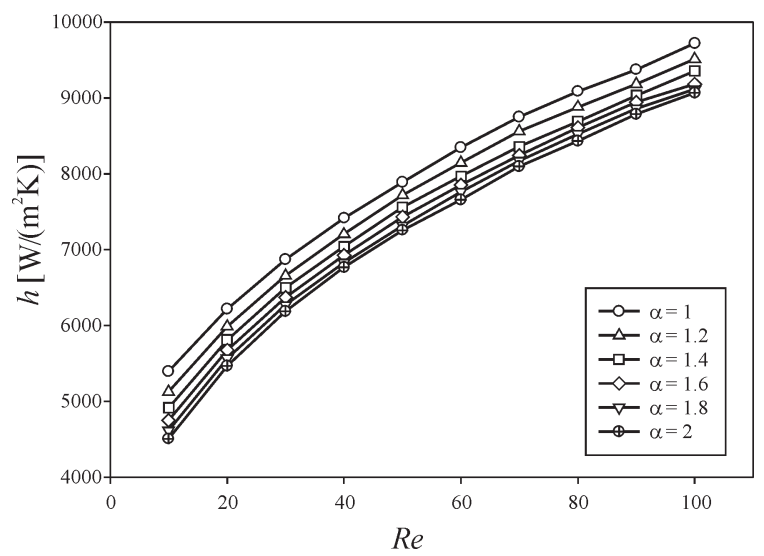

Fig. 6. The variation of convective heat transfer coefficient with the Reynolds number for different aspect ratios (working fluid is pure EG)

at $R e=10$ and $R e=100$ is higher my $19.69 \%$ and $7.18 \%$ compared to that of $\alpha=2.0$, respectively. The microchannel having an aspect ratio of $\alpha=1$ provides better heat dissipation by convection heat transfer. The microchannel width is decreased with increasing aspect ratio to be able to provide constant hydraulic diameter. This tendency causes decreases in the heated surface area of the microchannel and consequently increases the convective heat transfer coefficient. However, a decrease in the outlet temperature of pure EG with increasing aspect ratio is higher than the decrease in heated surface area. Therefore, the convective heat transfer coefficient decreases with the increasing aspect ratio of the microchannel.

The variation of convective heat transfer coefficient with the Reynolds number for different nanoparticle volume fractions in $\alpha=1$ is illustrated in Fig. 7.

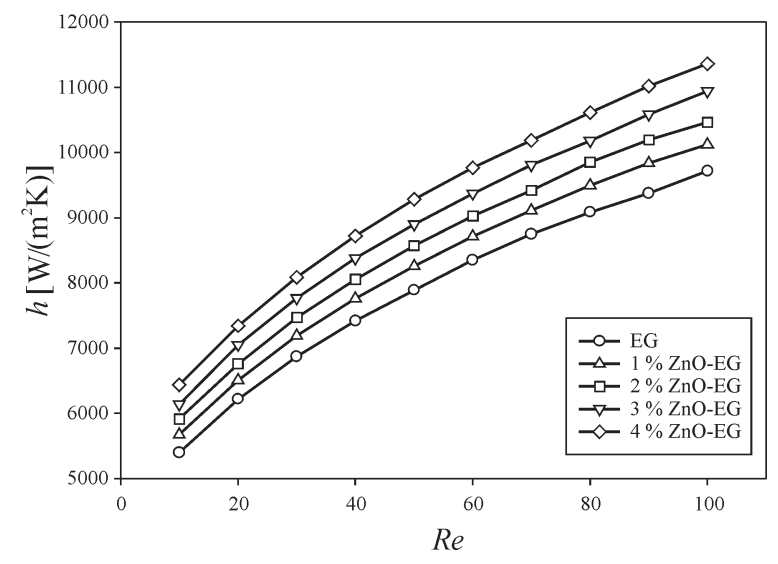

Fig. 7. The variation of convective heat transfer coefficient with the Reynolds number for different nanoparticle volume fractions (for $\alpha=1$ )

The convective heat transfer coefficient increases with the increase in nanoparticle volume fraction of $\mathrm{ZnO}-\mathrm{EG}$ nanofluid. The increments in the convective heat transfer coefficient for $4 \% \mathrm{ZnO}$ EG nanofluid compared to pure EG is $19.33 \%$ and $16.89 \%$ at $R e=10$ and $R e=100$, respectively. The $\mathrm{ZnO}$ nanoparticle addition to pure EG increases the density, outlet temperature of the nanofluid, and the velocity of the nanofluid at fixed Reynolds numbers. Moreover, the $\mathrm{ZnO}$ nanoparticle addition to pure EG decreases the temperature difference between wall and bulk temperatures of nanofluid. This fact is also reported by Tsai and Chein [22]. These facts increase the convective heat transfer coefficient of flow. The specific heat of pure EG decreases with increasing nanoparticle volume fraction. This case has a reducing effect on the convective heat transfer coefficient but is eliminated by other additive effects.

The variation of local convective heat transfer coefficient along with axial dimensionless distance for each aspect ratio of the rectangular microchannel 

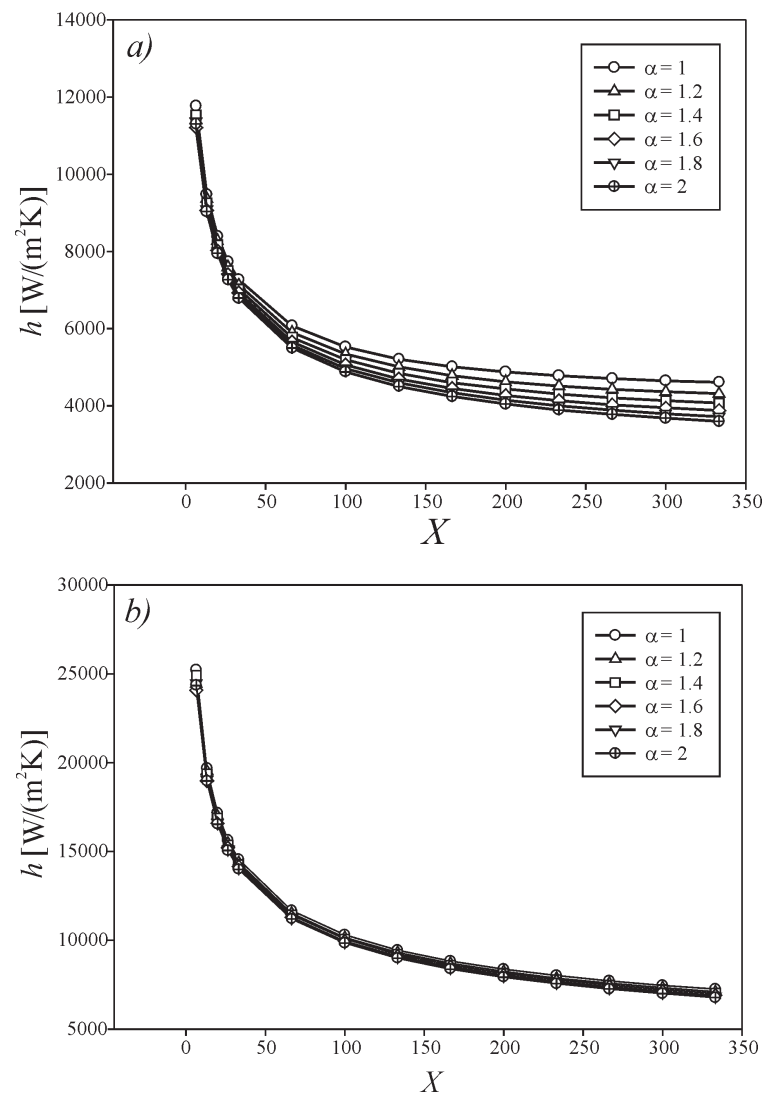

Fig. 8. The variation of local convective heat transfer coefficient along with axial dimensionless distance for different aspect ratios (working fluid is pure EG) at a) $R e=10$ and b) $R e=100$

in the use of pure EG at $R e=10$ and $R e=100$ are illustrated in Figs. 8a and b, respectively.

As can be seen from Figs $8 \mathrm{a}$ and $\mathrm{b}$, the local convective heat transfer values are much higher in the inlet region of the microchannel. It is also observed that the reduction in local convective heat transfer coefficient after the inlet region of the microchannel at $R e=100$ is higher compared to that of at $R e=10$.

The variation of local convective heat transfer coefficient along with the axial dimensionless distance for different nanoparticle volume fractions in $\alpha=1$ at $R e=10$ and $R e=100$ are illustrated in Figs. 9a and b, respectively.

As expected, the local convective heat transfer coefficients for $4 \%$ ZnO-EG nanofluid take higher values in comparison to other nanoparticle volume fractions of $\mathrm{ZnO}-\mathrm{EG}$ nanofluid and pure EG. It is also observed that the $\mathrm{ZnO}$-EG nanofluid flow is thermally developing a flow for this study.
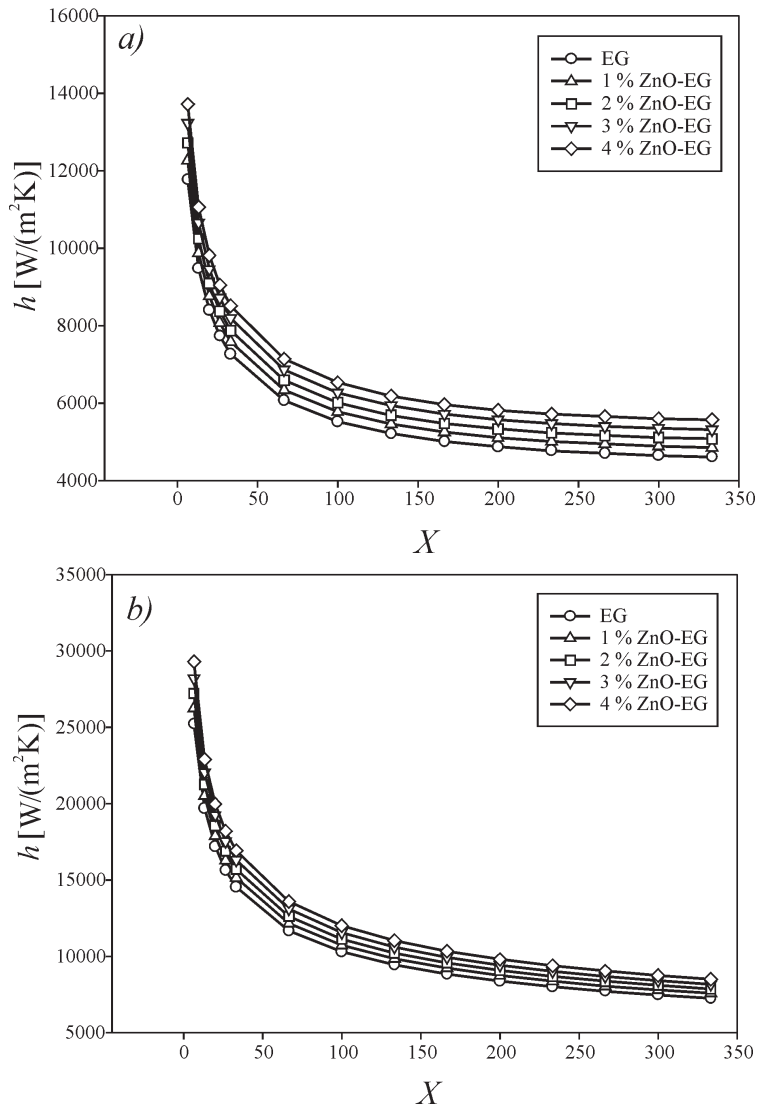

Fig. 9. The variation of local convective heat transfer coefficient along with axial dimensionless distance for different nanoparticle volume fractions $(\alpha=1)$ at a) $R e=10$ and $b) \operatorname{Re}=100$

\subsection{The Nusselt Number}

The Nusselt number is expressed as follows:

$$
N u=\frac{h D_{h}}{k} .
$$

The variation of the Nusselt number with the Reynolds number for each aspect ratio of the rectangular microchannel in the use of pure EG is illustrated in Fig. 10.

The Nusselt number decreases with increases in the aspect ratio of the rectangular microchannel. It is found that the Nusselt number obtained for $\alpha=1$ at $\operatorname{Re}=10$ and $\operatorname{Re}=100$ is higher by $19.69 \%$ and $7.18 \%$ compared to that of $\alpha=2$, respectively.

The variation of the Nusselt number with the Reynolds number for different nanoparticle volume fractions in $\alpha=1$ is illustrated in Fig. 11.

As can be seen from Fig. 11, the Nusselt number surprisingly decreases with increases in nanoparticle 
volume fraction of $\mathrm{ZnO}-\mathrm{EG}$ nanofluid. The Nusselt number values for $4.0 \% \mathrm{ZnO}-\mathrm{EG}$ nanofluid at $R e=10$ and $R e=100$ are lower by $2.02 \%$ and $4.02 \%$ compared to that of pure EG, respectively.

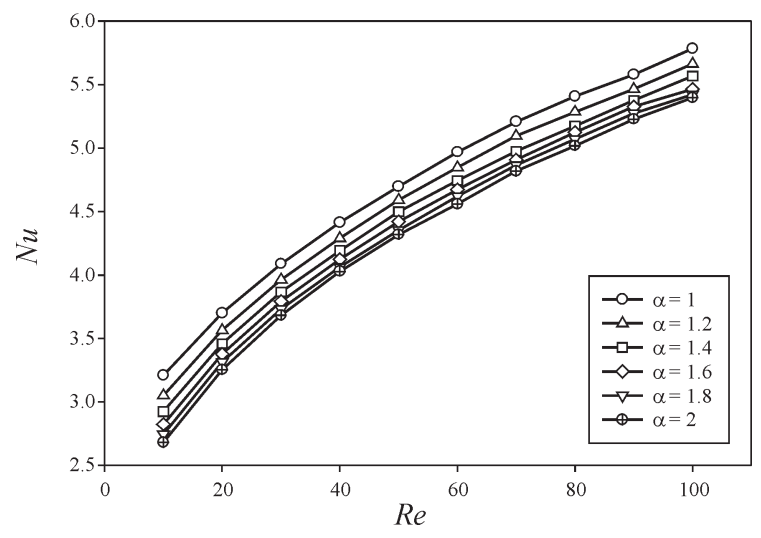

Fig. 10. The variation of the Nusselt number with the Reynolds number for different aspect ratios (working fluid is pure EG)

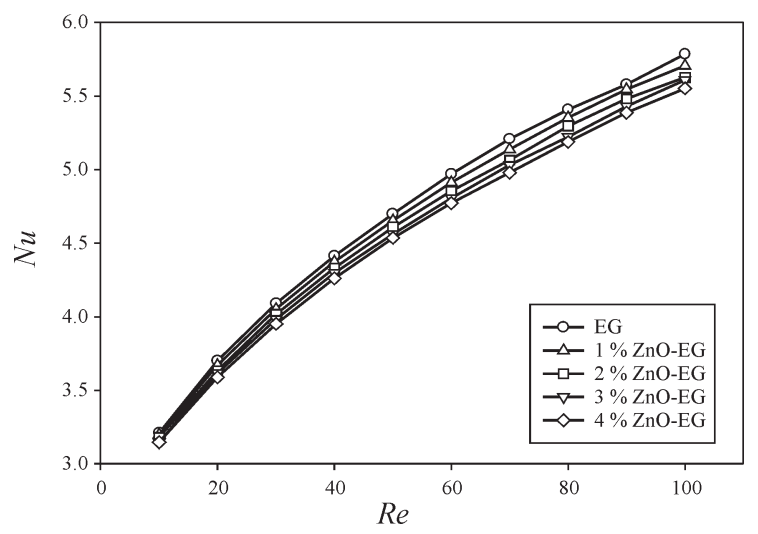

Fig. 11. The variation of the Nusselt number with the Reynolds number for different nanoparticle volume fractions (for $\alpha=1$ )

The reason for the decrease in the Nusselt number is a higher increment in conductive heat transfer coefficient when $\mathrm{ZnO}$ nanoparticle is added to pure EG. The increment in convective heat transfer coefficient is obtained to be $19.33 \%$ for $4 \% \mathrm{ZnO}-\mathrm{EG}$ nanofluid at $R e=10$, while the increment in conductive heat transfer coefficient is $21.78 \%$ for $4 \% \mathrm{ZnO}-\mathrm{EG}$ nanofluid. This higher increment in conductive heat transfer coefficient compared to convective heat transfer coefficient reduces the Nusselt number of the flow.

\subsection{Pressure Drop}

The variation of normalized pressure drop with the Reynolds number for each aspect ratio of the rectangular microchannel in the use of pure EG is illustrated in Fig. 12.

The normalized pressure drop increases with increases in aspect ratio of the rectangular microchannel. It is found that the normalized pressure drop for $\alpha=2$ at $R e=10$ and $R e=100$ is $9.05 \%$ and $8.91 \%$ higher compared to that of $\alpha=1$, respectively.

The variation of normalized pressure drop with the Reynolds number for different nanoparticle volume fractions in $\alpha=1$ is illustrated in Fig. 13, respectively.

It is found that the normalized pressure drop increases with increases in nanoparticle volume fraction of $\mathrm{ZnO}-\mathrm{EG}$ nanofluid in that $\mathrm{ZnO}$ nanoparticle addition to pure EG increases the viscosity of the nanofluid. The normalized pressure drop values for $4 \% \mathrm{ZnO}$-EG nanofluid at $R e=10$ and $R e=100$ are $28.96 \%$ and $29.23 \%$ higher compared to that of pure EG, respectively.

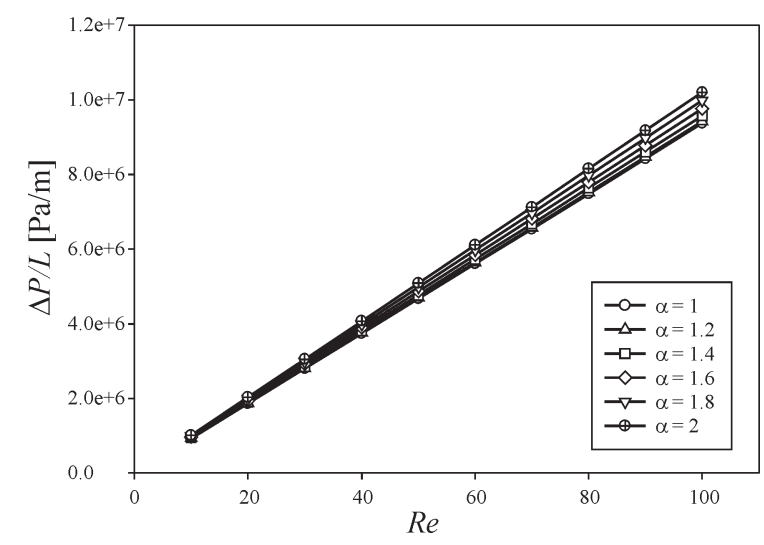

Fig. 12. The variation of normalized pressure drop with the Reynolds number for different aspect ratios (working fluid is pure $E G$ )

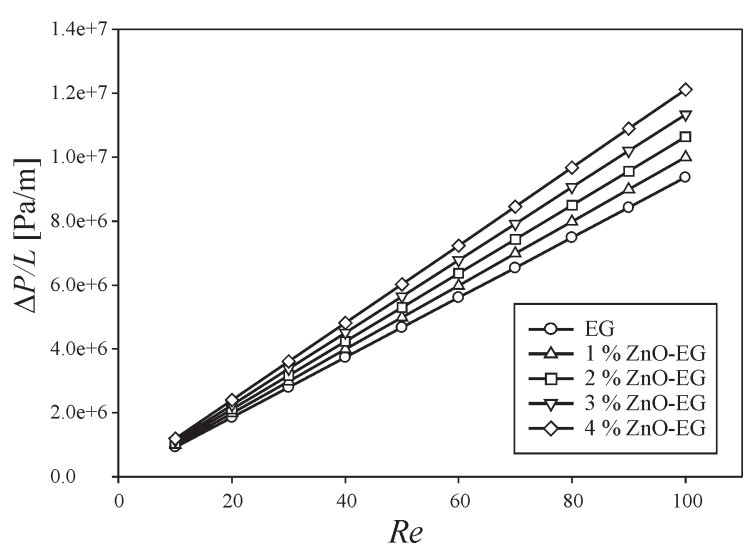

Fig. 13. The variation of normalized pressure drop with the Reynolds number for different nanoparticle volume fractions (for $\alpha=1)$ 


\subsection{The Darcy Friction Factor}

The Darcy friction factor is determined as follows:

$$
f=2 \frac{D_{h}}{L} \frac{\Delta P}{\rho U_{i n}^{2}},
$$

where $L$ is the length of the microchannel, $\Delta P$ is the pressure drop.

The variation of the Darcy friction factor with the Reynolds number for each aspect ratio of the rectangular microchannel in the use of pure EG is illustrated in Fig. 14.

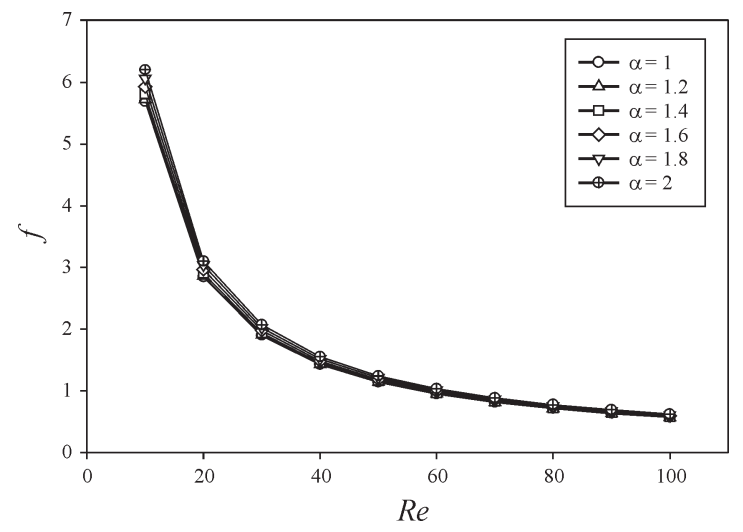

Fig. 14. The variation of the Darcy friction factor with the Reynolds number for different aspect ratios (working fluid is pure EG)

The Darcy friction factor increases with increases in the aspect ratio of the rectangular microchannel. The pressure drop for $\alpha=2$ at $R e=10$ and $R e=100$ is $9.05 \%$ and $8.91 \%$ higher compared to that of $\alpha=1$, respectively.

The variation of the Darcy friction factor with the Reynolds number for different nanoparticle volume fractions in $\alpha=1$ is illustrated in Fig. 15.

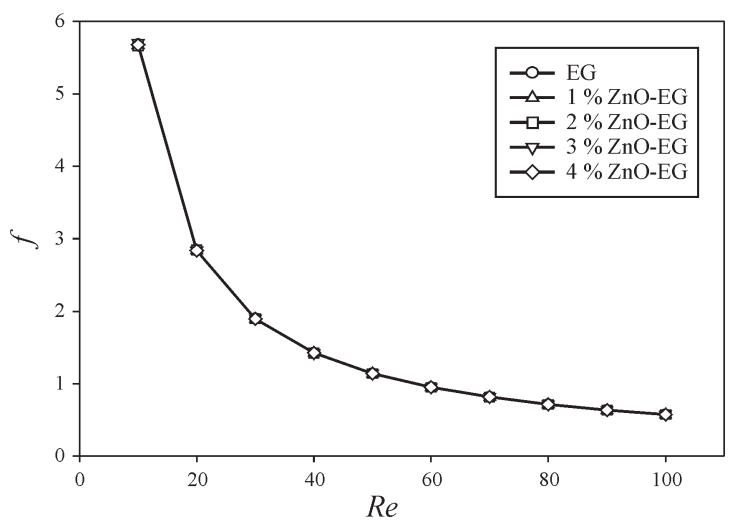

Fig. 15. The variation of the Darcy friction factor with the Reynolds number for different nanoparticle volume fractions (for $\alpha=1$ )
It is observed that the $\mathrm{ZnO}$ nanoparticle addition to pure EG does not affect the Darcy friction factor. The same finding is reported for $\mathrm{Al}_{2} \mathrm{O}_{3}$-water and $\mathrm{Al}_{2} \mathrm{O}_{3}$-EG/water nanofluids by Jung et al. [23].

The local Darcy friction factor can be calculated as follows

$$
f_{x}=\frac{8 \tau_{x}}{\rho U_{i n}^{2}},
$$

where $\tau_{x}$ is local shear stress.

The variation of the local Darcy friction factor along with axial dimensionless distance for each aspect ratio of the rectangular microchannel in the use of pure $\mathrm{EG}$ at $R e=10$ and $R e=100$ are illustrated in Figs. 16a and b, respectively.
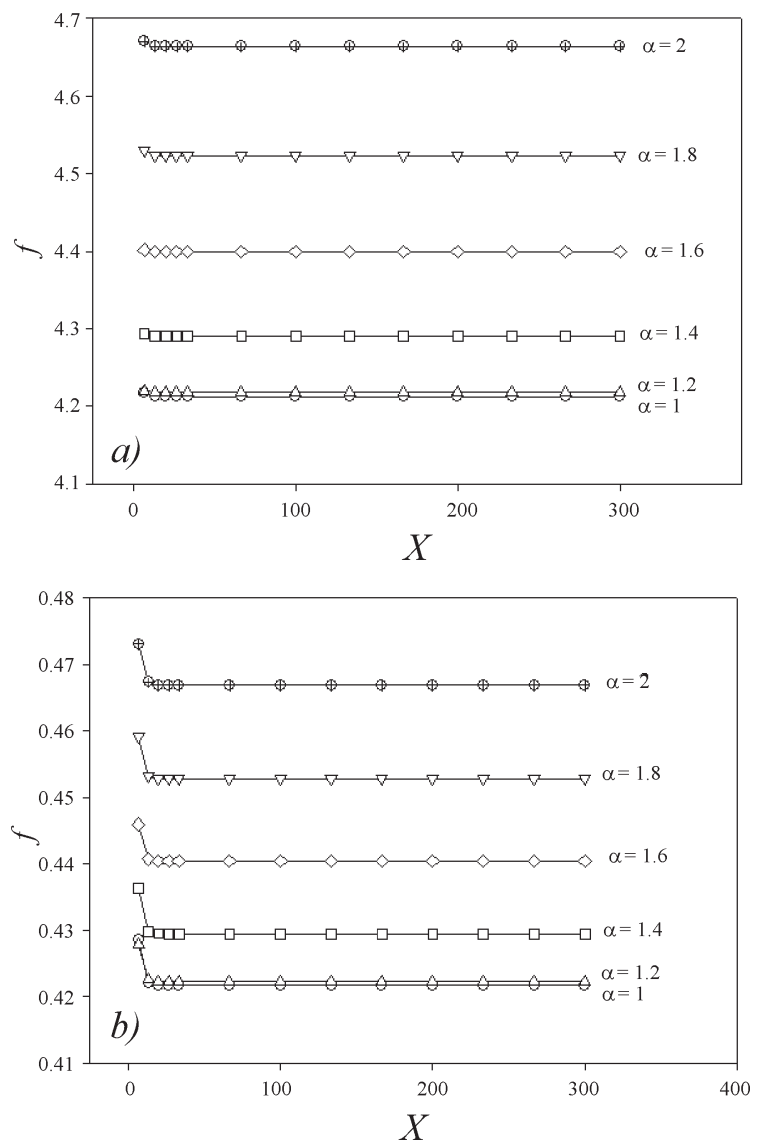

Fig. 16. The variation of the local Darcy friction factor along with axial dimensionless distance for different aspect ratios (working fluid is pure $E G$ ) at a) $R e=10$ and b) $R e=100$

As can be seen from Figs 16a and $b$, the flow is hydrodynamically developed. The velocity of flow and the local shear stress values increase with an increase in the Reynolds number. However, an increase in velocity is higher than that of local shear 
stress. Therefore, the local Darcy friction values for $R e=10$ are higher than that of $R e=100$. The highest local Darcy friction factor values along with the axial dimensionless distance are obtained for $\alpha=2$, while the lowest values are obtained for $\alpha=1$. The surface area of a microchannel increases with increases in aspect ratio of the microchannel. A larger surface area leads to increases in local shear stress.

\subsection{Thermal Resistance and Pumping Power}

Thermal resistance can be defined as follows:

$$
R_{t h}=\frac{T_{w}-T_{i n}}{Q_{i n}},
$$

where $Q_{i n}$ is the amount of heat transferred to nanofluid.

Another important parameter is the pumping power required to drive the nanofluid through the microchannel. The pumping power required can be written as:

$$
W=U_{\text {in }} A_{c} \Delta P,
$$

where $A_{c}$ is the cross-section area of the microchannel.

The increase in nanoparticle volume fraction of ZnO-EG nanofluid reduces the wall temperature. Therefore, the increase in the nanoparticle volume fraction of $\mathrm{ZnO}-\mathrm{EG}$ nanofluid caused a reduction in thermal resistance.

The nanoparticle addition to working fluid also increases the pressure drop and, therefore, the pumping power increases. The nanofluids should be evaluated by their thermal resistance in a given pumping power.

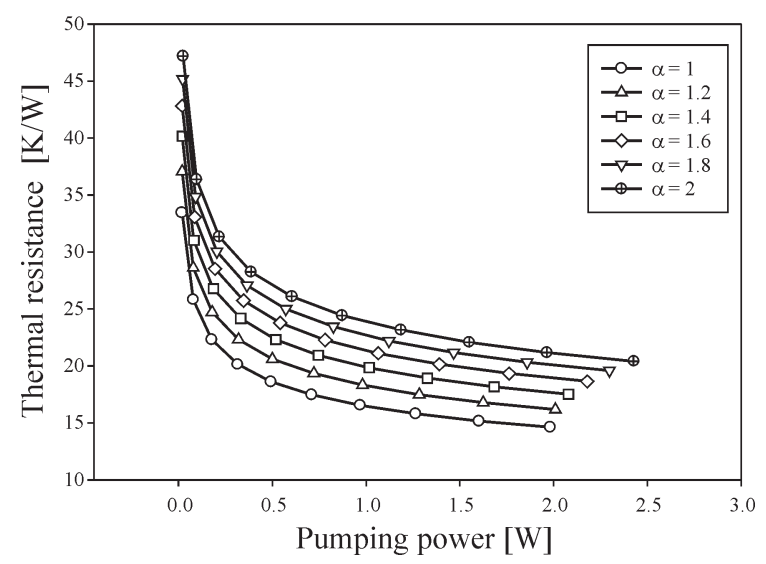

Fig. 17. The variation of thermal resistance with pumping power required for different aspect ratios (working fluid is pure EG)
The variation of the thermal resistance with pumping power required for each aspect ratios of the rectangular microchannel in the use of pure EG is illustrated in Fig. 17.

In a given pumping power required, the highest thermal resistance values are obtained for $\alpha=2$, while the lowest values are obtained for $\alpha=1$.

The variation of thermal resistance with pumping power required for different nanoparticle volume fractions of $\mathrm{ZnO}$-EG nanofluid in $\alpha=1$ is illustrated in Fig. 18.

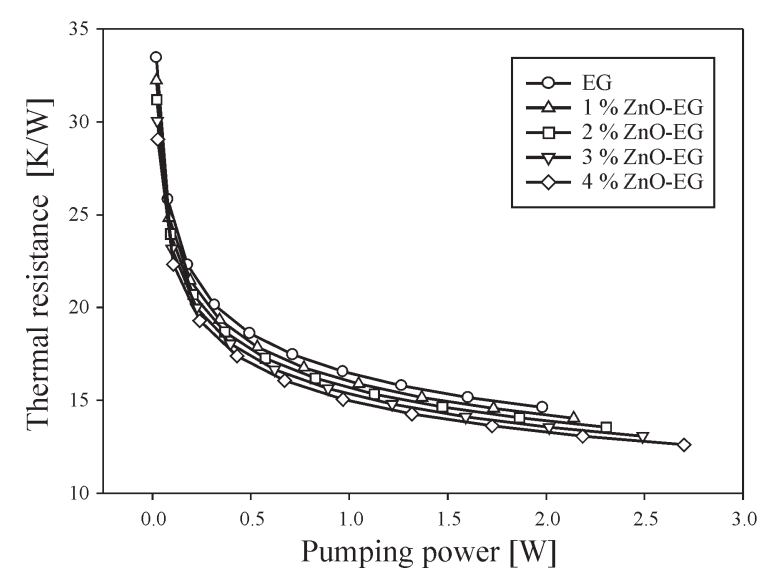

Fig. 18. The variation of thermal resistance with pumping power required for different aspect ratios (working fluid is pure EG)

In a given pumping power, the highest thermal resistance values are obtained for pure EG. The thermal resistance decreases with increases in the nanoparticle volume fraction of $\mathrm{ZnO}-\mathrm{EG}$ nanofluid. The lowest thermal resistance values for a required pumping power are obtained for $4 \%$ ZnO-EG nanofluid.

\section{CONCLUSIONS}

The fluid flow and heat transfer characteristics of $\mathrm{ZnO}$ EG nanofluid through rectangular microchannels with different aspect ratios are numerically investigated. The results showed that the geometrical configuration of microchannels is a very effective parameter on fluid flow and heat transfer characteristics. Therefore, the hydrodynamic and thermal performances of microchannels can be enhanced with only geometric configuration in the system design. The microchannel with $\alpha=1$ gave better results in the sense of both fluid flow and heat transfer. In the analyses, the different nanoparticle volume fractions of $\mathrm{ZnO}-\mathrm{EG}$ nanofluid are used as a working fluid. The use of ZnO-EG nanofluid enhanced the convection heat transfer; 
however, it simultaneously increased the pressure drop. In this case, the thermal resistance value at a given pumping power provides insight about the advantage or disadvantage of nanofluid use. ZnO-EG nanofluid has an advantage over pure EG due to their lower thermal resistance values at a given pumping power compared to pure EG.

\section{REFERENCES}

[1] Choi, S.U.S. (1995). Enhancing thermal conductivity of fluids with nanoparticles. ASME FED, vol. 231, p. 99-103.

[2] Azizi, Z., Alamdari A., Malayeri, M.R. (2015). Convective heat transfer of Cu-water nanofluid in a cylindrical microchannel heat sink. Energy Conversion and Management, vol. 101, p. 515-524, DOI:10.1016/j.enconman.2015.05.073.

[3] Rimbault, B., Nguyen, C.T., Galanis, N. (2014). Experimental investigation of CuO-water nanofluid flow and heat transfer inside a microchannel heat sink. International Journal of Thermal Sciences, vol. 84, p. 275-292, Dol:10.1016/j. ijthermalsci.2014.05.025.

[4] Kalteh, M. (2013). Investigating the effect of various nanoparticle and base liquid types on the nanofluids heat and fluid flow in a microchannel. Applied Mathematical Modeling, vol. 37, no. 18-19, p. 8600-8609, Dol:10.1016/j. apm.2013.03.067.

[5] Halelfadl, S., Adham, A.M., Mohd-Ghazali, N., Maré, T., Estellé, P., Ahmad, R. (2014). Optimization of thermal performances and pressure drop of rectangular microchannel heat sink using aqueous carbon nanotubes based nanofluid. Applied Thermal Engineering, vol. 62, no. 2, p. 492-499, Dol:10.1016/j. applthermaleng.2013.08.005.

[6] Zhang, H., Shao, S., Xu, H., Tian, C. (2013). Heat transfer and flow features of Al203-water nanofluids flowing through a circular microchannel -Experimental results and correlations. Applied Thermal Engineering, vol. 61, no. 2, p. 86-92, DOI:10.1016/j.applthermaleng.2013.07.026.

[7] Nebbati, R., Kadja, M. (2015). Study of forced convection of a nanofluid used as a heat carrier in a microchannel heat sink. Energy Procedia, vol. 74, p. 633-642, Dol:10.1016/j. egypro.2015.07.799.

[8] Mohammed, H.A., Gunnasegaran, P., Shuaib, N.H. (2010). Heat transfer in rectangular microchannels heat sink using nanofluids. International Communications in Heat and Mass Transfer, vol. 37, no. 10, p. 1496-1503, Dol:10.1016/j. icheatmasstransfer.2010.08.020.

[9] Mohammed, H.A., Gunnasegaran, P., Shuaib, N.H. (2011). The impact of various nanofluid types on triangular microchannels heat sink cooling performance. International Communications in Heat and Mass Transfer, vol. 38, no. 6, p. 767-773, D0l:10.1016/j.jijheatmasstransfer.2011.03.024.

[10] Salman, B.H., Mohammed, H.A., Kherbeet, A.Sh. (2014). Numerical and experimental investigation of heat transfer enhancement in a microtube using nanofluids. International
Communications in Heat and Mass Transfer, vol. 59, p. 88100, D0l:10.1016/j.icheatmasstransfer.2014.10.017.

[11] Mohammed, H.A., Bhaskaran G., Shuaib, N.H., Abu-Mulaweh, H.I. (2011). Influence of nanofluids on parallel flow square microchannel heat exchanger performance. International Communications in Heat and Mass Transfer, vol. 38, no. 1, p. 1-9, D0I:10.1016/j.icheatmasstransfer.2010.09.007.

[12] Vajjha, R.S., Das, D.K. (2009). Specific heat measurement of three nanofluids and development of new correlations. ASME Journal of Heat Transfer, vol. 131, no. 7, 071601, p. 1-7, DOI:10.1115/1.3090813.

[13] Satti, J.R., Das, D.K., Ray, D. (2016). Specific heat measurements of five different propylene glycol based nanofluids and development of a new correlation. International Journal of Heat and Mass Transfer, vol. 94, p. 343-353, D0I:10.1016/j.ijheatmasstransfer.2015.11.065.

[14] Esfe, M.H., Saedodin, S. (2014). Experimental investigation and proposed correlations for temperature-dependent thermal conductivity enhancement of ethylene glycol based nanofluid containing ZnO nanoparticles. Journal of Heat and Mass Transfer Research, vol. 1, no. 1, p. 47-54.

[15] Esfe, M.H., Saedodin, S. (2014). An experimental investigation and new correlation of viscosity of ZnO-EG nanofluid at various temperatures and different solid volume fractions. Experimental Thermal and Fluid Sciences, vol. 55, p.1-5, D0I:10.1016/j.expthermflusci.2014.02.011.

[16] Yu, W., Xie, H., Chen, L., Li, Y. (2009). Investigation of thermal conductivity and viscosity of ethylene glycol based $\mathrm{ZnO}$ nanofluid. Thermochimica Acta, vol. 491, no. 1-2, p. 92-96, D0I:10.1016/j.tca.2009.03.007.

[17] Prajapati, O.S., Rohatgi, N., Rajvanshi, A.K. (2013). Heat transfer behavior of nano-fluid at high pressure. Journal of Materials Science and Surface Engineering, vol. 1, no. 1, p. 1-3.

[18] Salman, B.H., Mohammed, H.A., Munisamy, K.M., Kherbeet, A.Sh. (2014). Three-dimensional numerical investigation of nanofluids flow in microtube with different values of heat flux. Heat Transfer-Asian Research, vol. 44, no. 7, p. 599-619, DOI:10.1002/htj.21139.

[19] Das, S.K., Choi, S.U.S., Yu, W., Pradeep, T. (2008). Nanofluids: Science and Technology. John Wiley \& Sons, Jersey.

[20] Patankar, S.V. (1980). Numerical Heat Transfer and Fluid Flow. Hemisphere Publishing Corporation, Washington.

[21] Lee, P.S., Garimella, S.V., Liu, D. (2005). Investigation of heat transfer in rectangular microchannels. International Journal of Heat and Mass Transfer, vol. 48, no. 9, p. 1688-1704, DOl:10.1016/j.ijheatmasstransfer.2004.11.019.

[22] Tsai, T.H., Chein, R. (2007). Performance analysis of nanofluidcooled microchannel heat sinks. International Journal of Heat and Fluid Flow, vol. 28, no. 5, p. 1013-1026, D0l:10.1016/j. ijheatfluidflow.2007.01.007.

[23] Jung, J.Y., Oh, H.S., Kwak, H.Y. (2009). Forced convective heat transfer of nanofluids in microchannels. International Journal of Heat and Mass Transfer, vol. 52, no. 1-2, p. 466-472, DOI:10.1016/j.ijheatmasstransfer.2008.03.033. 